\title{
High-Speed Laser-Launched Flyer Impacts Studied with Ultrafast Photography and Velocimetry
}

\author{
Alexandr A. Banishev ${ }^{1} \cdot$ William L. Shaw ${ }^{1} \cdot$ Will P. Bassett $^{1} \cdot{\text { Dana D. } \text { Dlott }^{1}}$
}

Received: 11 January 2016/Accepted: 11 February 2016/Published online: 16 February 2016

(C) Society for Experimental Mechanics, Inc 2016

\begin{abstract}
Pulsed lasers can launch thin metal foils at $\mathrm{km} \mathrm{s}^{-1}$, but for precision measurements in shock compression science and shock wave spectroscopy, where onedimensional shock compression is vital, flyer plate impacts with targets must have a high degree of flatness and minimal tilt, and the flyer speeds and impact times at the target must be highly reproducible. We have developed an apparatus that combines ultrafast stroboscopic optical microscopy with photon Doppler velocimetry to study impacts of laser-launched $\mathrm{Al}$ and $\mathrm{Cu}$ flyer plates with flat, transparent glass targets. The flyer plates were $0.5 \mathrm{~mm}$ in diameter, and ranged from 12 to $100 \mu \mathrm{m}$ thick, with flyer speeds up to $6.25 \mathrm{~km} \mathrm{~s}^{-1}$. The velocity variations over 30-60 launches from the same flyer plate optic can be as low as $0.6 \%$, and the impact time variations can be as low as $0.8 \mathrm{~ns}$. Stroboscopic image streams (reconstructed movies) show uniform, flat impacts with a glass target. These stroboscopic images can be used to estimate the tilt in the flyer-target impact to be $<1 \mathrm{mrad}$.
\end{abstract}

Keywords High-speed impact Flyer plate $\cdot$ Shock generation · Ultrafast microscopy

Dana D. Dlott

dlott@illinois.edu

1 School of Chemical Sciences, University of Illinois at Urbana-Champaign, Box 01-6 CLSL, 600 S. Mathews Ave., Urbana, IL 61801, USA

\section{Introduction}

Pulsed lasers can launch thin metal foils at high velocities, for example $13 \mathrm{~km} \mathrm{~s}^{-1}$ using a tabletop laser [1] or a large laser facility [2]. But for precision measurements in shock compression science and shock wave spectroscopy, where one-dimensional shock compression is vital [3, 4], flyer plate impacts with targets must be as sudden as possible, with a high degree of flatness and minimal tilt, and the flyer speeds and impact times at the target must be reproducible. In light gas guns, where long projectiles and precisionmachined bores can be used, impact tilts of $3.5 \mathrm{mrad}$ [5] and $0.9 \mathrm{mrad}$ have been measured [6,7]. Factors such as flatness and tilt have not been studied in as much detail for laser-driven flyers, and they are of particular concern due to the small thickness of laser-launched flyer plates [8-11] and the possibility of spatially nonuniform launch laser beams [11-15]. Here we combined ultrafast stroboscopic microscopy, using a femtosecond white-light supercontinuum strobe, with photon Doppler velocimetry (PDV) [1618] to study the impacts of $0.5 \mathrm{~mm}$ diameter $\mathrm{km} \mathrm{s}^{-1}$ laserlaunched $\mathrm{Al}$ and $\mathrm{Cu}$ flyer plates with flat transparent glass targets. PDV uses a high-speed laser interferometer, where the flyer plate forms one arm of the interferometer and the flyer velocity history is derived from the time-dependent interferogram [16-19]. In previous works [17, 18], we investigated the laser launching and target impact processes with PDV, using $\mathrm{Al}$ flyers that were about $0.5 \mathrm{~mm}$ in diameter and $25-75 \mu \mathrm{m}$ thick. The flyer plate thickness is important in that it determines the duration of the fullysupported shock in the target $[18,20]$. Here we have extended previous PDV measurements of $25 \mu \mathrm{m}$ thick Al flyer reproducibility [18] to $\mathrm{Cu}$ flyers $\left(\rho=8.96 \mathrm{~g} \mathrm{~cm}^{-3}\right)$ and to thicker $\operatorname{Al}\left(\rho=2.70 \mathrm{~g} \mathrm{~cm}^{-3}\right)$ flyers. But the unique feature of this study is the use of ultrafast optical 
microscopy. Our PDV uses a laser beam that probes the average behavior of the central $70 \mu \mathrm{m}$ of the flyer plate [18], whereas with ultrafast microscopy we can see and assess the flatness and tilt of the entire flyer surface, including the outer edges.

The simplest method of laser flyer launching involves focusing a nanosecond high-energy laser pulse onto a sheet of metal foil [1,21], or onto a flyer plate optic consisting of a sheet of foil bonded to a transparent window [22]. The usual mechanism of flyer launch involves creating a metal plasma in a thin layer of the foil facing the laser [13, 2325]. Rapid expansion of the plasma propels a disk of foil away from the foil sheet, creating the laser-driven flyer plate. An alternative to the flyer plate optic is to fabricate the flyer plates as individual disks on a window $[9,10,22$, 26] or fiberoptic surface $[14,15,27]$. This fabrication avoids the edge effects involved in tearing disks away from a sheet, but is less convenient. With a $50 \times 50 \mathrm{~mm}^{2}$ flyer plate optic, we can launch 30-60 identical flyer plates in a short time, whereas fabricating individual flyer plates introduces complexities that significantly reduce the number of flyers that can be shot.

High-speed imaging has been previously used by Frank and Trott [23] and by Trott [25] to study laser flyer launches. Those authors visualized the launch plasma and the surface of the flyer plate shortly after launch, but did not image the target impact process that is the primary focus of the present study. Yu et al. [13] used right-angle imaging (shadowgraphy) with a high-speed camera to visualize $\mathrm{Cu}$ flyers. They were able to observe the different plasmas with and without a black paint absorbing layer, and they were also able to see the curvature of the flyer surface. Rupp et al. [28] used a two-camera stereo reconstruction method with a $10 \mathrm{~ns}$ duration strobe to image the surfaces of $3 \mathrm{~mm}$ diameter flyers made from $50 \mu \mathrm{m} \mathrm{Cu}$ or $100 \mu \mathrm{m} \mathrm{Ti}$. The Ti flyers, launched at about $0.5 \mathrm{~km} \mathrm{~s}^{-1}$ by a nominally flat top beam with intensity spikes, showed bowing of $\sim 30 \mu \mathrm{m}$ [28], which indicates that the variation in arrival time at a flat target would be on the order of $60 \mathrm{~ns}$. Zhao et al. [11] imaged the impact of a flyer with a glass target using an array of 12 optical fibers attached to fast photodetectors. The outputs of three of these photodetectors was used to conclude that the planarity of the impact was "good". Paisley et al. [26] and Greenfield et al. [29] used transient imaging displacement interferometry (TIDI) to study the surfaces of $0.1-2 \mathrm{~mm}$ thick $\mathrm{Cu}$ flyers in the form of $8 \mathrm{~mm}$ precut disks with carbon underlayers. The flyers were launched by a facility-sized $500 \mathrm{~J}$ laser TRIDENT, at speeds of $0.1-0.5 \mathrm{~km} \mathrm{~s}^{-1}$ [26]. The TIDI experiments showed a $400 \mu \mathrm{m}$ diameter, $2 \mu \mathrm{m}$ high bump at the center of $0.1 \mathrm{~mm}$ thick flyers, but not in thicker flyers, caused by a central hot spot in the launch beam. A $\leq 3 \mathrm{mrad}$ convex bowing of the flyer was observed, indicating that the edges of the $8 \mathrm{~mm}$ diameter flyer trailed the center region by about $12 \mu \mathrm{m}$. At a speed of $0.1 \mathrm{~km} \mathrm{~s}^{-1}$, a $2 \mu \mathrm{m}$ high bump at $0.1 \mathrm{~km} \mathrm{~s}^{-1}$ would impact a target $20 \mathrm{~ns}$ before the rest of the central flyer, and the edges would impact the target $120 \mathrm{~ns}$ after the center. At a speed of $0.5 \mathrm{~km} \mathrm{~s}^{-1}$, these different impact times would be reduced to 4 and $24 \mathrm{~ns}$.

The most common method for laser flyer launching, the ablation plasma-generation method [24], raises several concerns about the state of the flyer plate upon impact [10]. During launch and flight, the flyer plate loses mass, and upon impact the flyer consists of both liquid and hot solid materials. These concerns can be alleviated using ablative underlayers to launch the flyer $[2,8,10,26,30]$. In this case, the flyer itself is shielded from the laser beam, and it is launched by a laser-generated shock in the underlayers. Recently, our group has shown that it is possible to harness this shock launch mechanism without having to fabricate multilayers, using the shock-launch method described in Fig. 1 [17]. Sheets of $\mathrm{Al}$ or $\mathrm{Cu}$ foil were bonded to $6.35 \mathrm{~mm}$ thick $50 \times 50 \mathrm{~mm}^{2}$ borosilicate glass substrates by a $3.5 \mu \mathrm{m}$ epoxy layer [17]. A laser beam with a high degree of spatial uniformity (Fig. 1b), produced using a diffractive beam homogenizer, was focused onto the foil/glass interface [17]. The homogenizer was used in firstorder to eliminate the central hot spot created with zeroorder diffractive optics. The beam full-width half

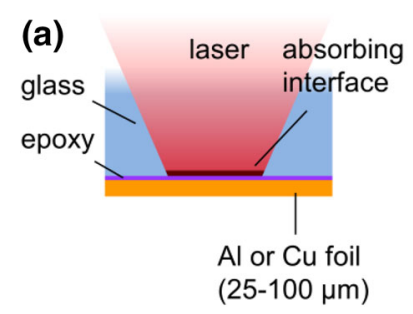

(b)

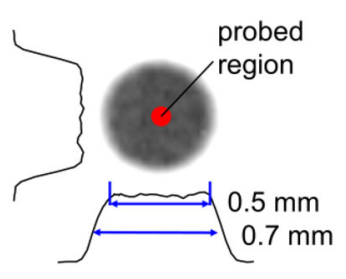

(c)

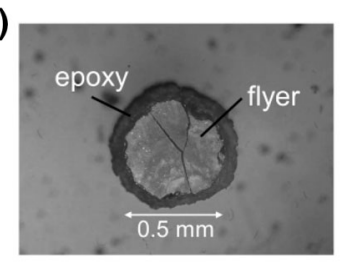

(d)

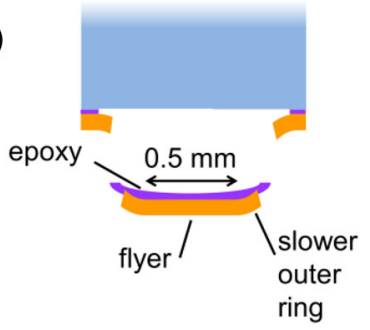

Fig. 1 a Schematic of flyer launch from a flyer plate optic consisting of metal foil bonded to a glass substrate. The flyer is launched by a shock created at the glass/epoxy interface. b Profile of the focused homogenized laser launch beam at the flyer plate. The uniform region is $0.5 \mathrm{~mm}$ in diameter and the FWHM is $0.7 \mathrm{~mm}$. PDV and spectroscopy experiments probe a $0.1 \mathrm{~mm}$ diameter region at the center of the flyer. c A flyer recovered after impacting a glass target at $1.7 \mathrm{~km} \mathrm{~s}^{-1}$, showing the flyer detached from the flyer plate optic at the glass/epoxy interface. $\mathbf{d}$ The uniform $0.5 \mathrm{~mm}$ center of the beam would be expected to launch a $0.5 \mathrm{~mm}$ flyer while the soft edges of the beam would be expected to launch a thin outer ring that trails the main flyer 
maximum was $0.7 \mathrm{~mm}$ and the uniform region at the beam center was $0.5 \mathrm{~mm}$, as shown in Fig. 1b. The focused pulse intensity greatly exceeded the surface damage threshold of glass at the glass/epoxy interface but not at the entrance face (the glass/air interface) where the beam was much larger and less intense. Most of the laser energy was absorbed by a thin layer of glass immediately adjacent to the epoxy layer [17]. Absorption at the glass/epoxy interface, denoted the "absorbing interface" in Fig. 1a, created a shock in the glass that launched the flyer. The evidence for this shock launch mechanism was summarized in Ref. [17]. Briefly: (1) only a small fraction of the incident light pulse was transmitted through the glass substrate; (2) visual inspection of recovered flyers (c.f. Fig. 1c) showed the flyer consisted of foil plus an epoxy underlayer, proving that the flyer detached at the glass/epoxy interface, and that the flyer at the metal/epoxy interface was not vaporized; (3) Multilayer flyer plate optics, where the flyers were shielded from the launch laser beam by additional underlayers of metal foil, had the same launch, flight and impact characteristics as unshielded flyers [17].

Figure 1c is a micrograph of one $25 \mu \mathrm{m}$ thick Al flyer recovered after a $1.7 \mathrm{~km} \mathrm{~s}^{-1}$ impact with glass. The flyer is close to $0.5 \mathrm{~mm}$ in diameter, while the epoxy underlayer is slightly larger. The $0.5 \mathrm{~mm}$ flyer diameter is indicative of the proposed scheme depicted in Fig. 1d, which is based on the observation that the launch beam has soft edges extending out to about $0.7 \mathrm{~mm}$. The uniform center of the beam propels a $0.5 \mathrm{~mm}$ disk at a higher speed than the soft edges of the beam, and some of the launch plasma near the disk edges escapes transversely [28], so a $0.5 \mathrm{~mm}$ foil flyer will be accompanied in flight by a thin slower trailing outer ring.

An example of a PDV flyer velocity history is shown in Fig. 2. A $75 \mu \mathrm{m}$ thick Al flyer was launched at a glass window across a $375 \mu \mathrm{m}$ vacuum gap, by a laser pulse arriving at time $t=0$. The velocity history in Fig. 2a was derived using the usual moving-window Fourier transform $[16,31]$ that gives a smoother time-averaged velocity history. The expanded view in Fig. $2 b$ used a fringecounting method described previously $[17,32]$ _ENREF_36, which gave higher time resolution with a bit more noise $[17,18,33]$. The free-space velocity of the flyer plate from Fig. 2a was $U_{f}=1.4( \pm 0.007) \mathrm{km} \mathrm{s}^{-1}$. At $354 \mathrm{~ns}$, the velocity dropped abruptly by $\sim 35 \%$, and this drop indicated the instant of impact with the glass target. The lower velocity, denoted $U_{p}$, is the velocity of the flyer/glass interface, or alternatively the material velocity in glass that drives a shock into the target. The value of $U_{p}$ remained approximately constant for a time interval $\tau_{s}$, where $\tau_{s}$ denotes the duration of the fully-supported shock in the window. Subsequent to the time interval $\tau_{s}, U_{p}$ declined and the shock pressure decayed. In Fig. 2a, $\tau_{s}=14 \mathrm{~ns}$, and the apparent velocity $U_{p}=0.878$ $( \pm 0.015) \mathrm{km} \mathrm{s}^{-1}$. When the flyer plate is moving through a solid transparent medium, an optical window correction should be applied to convert apparent velocity to true velocity. For borosilicate glass, the conversion factor is close to unity. The apparent velocity should be multiplied by 0.9410 [31]. The shock pressure in glass can be determined from the corrected $U_{p}$ using tabulated Hugoniot data [34], and here $P=9.0( \pm 0.15) \mathrm{GPa}$.

The errors in our PDV velocity measurements are generally about $1 \%$. Accuracy increases as the constant-velocity flight path increases. In the $U_{f}$ determination for this flyer, the flyer flew at constant velocity for $\sim 150 \mathrm{~ns}$ (Fig. 2a), and the fractional velocity error was $0.5 \%$. In the $U_{p}$ determination, the constant velocity in glass lasted $14 \mathrm{~ns}$ (Fig. 2b) and the fractional error was $1.7 \%$.

The key features of the measurement in Fig. $2 b$ are the suddenness of the transition from free flight at $U_{f}$ to shock drive at $U_{p}$, and the constancy of $U_{p}$ during the interval $\tau_{s}$. The sudden transition is indicative of an impact between two flat parallel surfaces. The observed time for the sudden transition is $<0.2 \mathrm{~ns}$, but an analysis of the time resolution of our PDV system [17, 18, 33] suggests a more conservative value of $0.5 \mathrm{~ns}$ is more appropriate. A transition time of $0.5 \mathrm{~ns}$ at $U_{f}=1.4 \mathrm{~km} \mathrm{~s}^{-1}$ indicates a tilt of
Fig. 2 PDV velocity history from a $1.4 \mathrm{~km} \mathrm{~s}^{-1}, 75 \mu \mathrm{m}$ thick Al flyer launched at a glass target by a laser pulse at $t=0$. After the reverberations die out the flyer travels at $1.4 \mathrm{~km} \mathrm{~s}^{-1}$ until it impacts the target. The impact at $354 \mathrm{~ns}$ is indicated by a sudden drop in velocity occurring in $<0.5 \mathrm{~ns}$
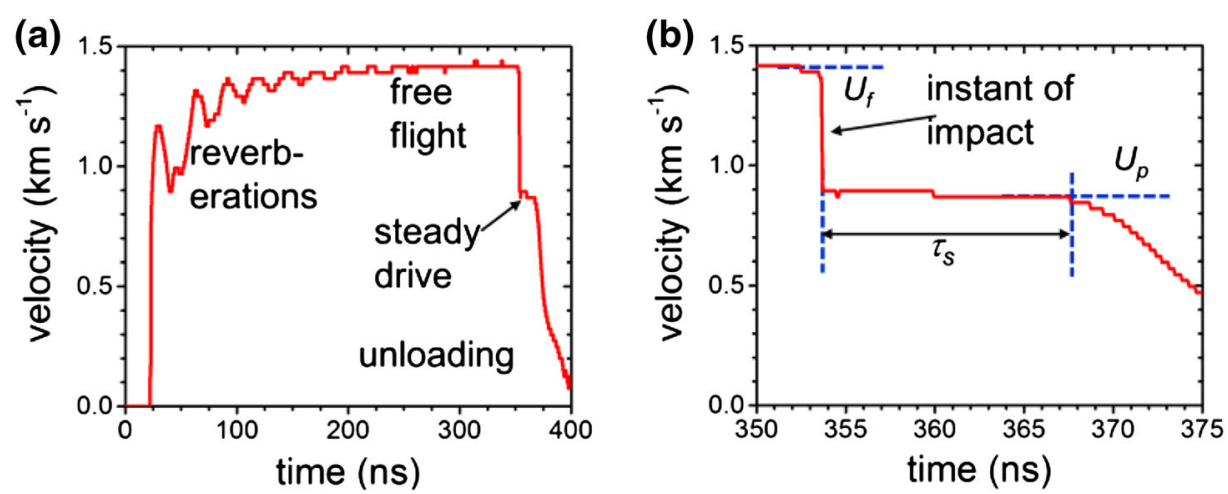
$<0.7 \mu \mathrm{m}$ over the $70 \mu \mathrm{m}$ diameter region probed by PDV, corresponding to a flyer tilt $<10 \mathrm{mrad}$.

In the rest of this paper, we describe the experimental apparatus, we present results showing flyer speed versus laser intensity for $\mathrm{Al}$ flyers 12, 25, 50, 75 and $100 \mu \mathrm{m}$ thick and $\mathrm{Cu}$ flyers 25 and $70 \mu \mathrm{m}$ thick. We present PDV results showing the measured variations in flyer speeds and target impact times. We then present ultrafast optical microscope images of impacts with glass targets that allow us to assess the significance of edge effects and the planarity of the impact over the entire surface of the flyer, rather than just the $70 \mu \mathrm{m}$ region probed by PDV.

\section{Experimental}

\section{Launch Laser and PDV}

The laser launch and PDV apparatus have been described in previous publications [17, 22]. Synchronization of the femtosecond strobe laser with the launch laser has also been described [35, 36]. A new feature needed to perform ultrafast strobe microscopy is the more stringent synchronization of the strobe laser with target impact as determined by PDV.

A block diagram for the ultrafast microscopy apparatus is shown in Fig. 3. The Nd:YAG launch laser (SpectraPhysics Quanta Ray Pro 350) can provide up to $2.5 \mathrm{~J}$ pulses with $10 \mathrm{~ns}$ duration. The pulses were beam expanded and sent into an all-reflective pulse stretcher [17, 37] which doubled the duration to $20 \mathrm{~ns}$. The stretched pulses produce a more gradual acceleration to reduce reverberating shocks

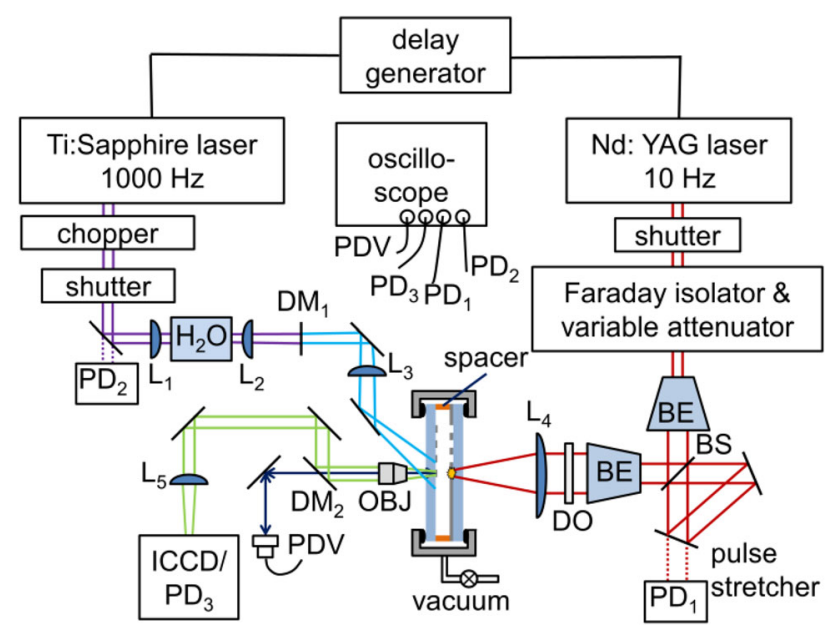

Fig. 3 Block diagram of apparatus for launching flyers and detecting flyer impacts. $P D$ photodiode, $P D V$ photon Doppler velocimeter, $B E$ beam expander, $B S$ beamsplitter, $L$ lens, $D M$ dichroic mirror, $D O$ diffractive optic, $O B J 10 \times$ infinity-corrected microscope objective, ICCD intensified charge-coupled device camera in the flyer [17]. After a second round of beam expansion to $60 \mathrm{~mm}$ diameter, the pulses were directed onto a first-order diffractive beam homogenizer (Silios) and focused onto the flyer plate optic to create the beam profile shown in Fig. 1b. The maximum pulse energy at the flyer plate optic was $2.0 \mathrm{~J}$. The strobe laser (Quantronix Integra C-2.0) consisted of a mode-locked fiber oscillator and chirped pulse amplifier that produced $2.0 \mathrm{~mJ}$ pulses at $785 \mathrm{~nm}$ with $140 \mathrm{fs}$ duration. These pulses were focused into a $5 \mathrm{~cm}$ long water cell to produce a supercontinuum. The supercontinuum is a subpicosecond burst of incoherent white light [38]. These incoherent pulses are desirable for imaging because they produce fewer coherent artifacts such as speckle.

\section{Sample chamber}

The flyer plate optic substrates and target windows were borosilicate glass $50 \times 50 \times 6.35 \mathrm{~mm}^{3}$, from Chemglass, mounted in a vacuum cell with a gap determined by the number of nominally $125 \mu \mathrm{m}$ thick plastic spacers used or by a single stainless steel spacer (Fig. 3). The flyer plate optic was fabricated by bonding a foil sheet to a glass window with low-viscosity Eccobond 24 water-clear epoxy [22] (Henkel Loctite). The foils were not perfect mirrorlike films, as vapor-deposited films might be. They had occasional scratches and the thinner foils had shiny surfaces, while the thicker foils had matte surfaces. We generally used the smallest gap needed for the launch reverberations to die out (e.g. Fig. 2a) and the flyers to reach terminal velocity, which was $125-500 \mu \mathrm{m}$ depending on flyer thickness and launch energy. The sample chamber was mounted on an $x y$ translator. Each time the launch laser was fired, the chamber was translated to expose a fresh spot on the flyer plate optic. We typically launched 30-60 flyers without opening the chamber to replace the flyer plate optic and target window. The number of flyers we launched with a single flyer optic depended on the spacing between laser shots, which in turn depended on how much each flyer shot disturbed the surrounding foil. The size of the disturbed regions increased with foil thickness and launch laser energy.

\section{Photon Doppler Velocimeter (PDV)}

The PDV uses a single-mode $1550 \mathrm{~nm}$ fiber laser and a fiber circulator and beam combiner to create an interferometer $[17-19,22,31]$. The $1550 \mathrm{~nm}$ output beam from the single-mode fiber was collimated to $600 \mu \mathrm{m}$ diameter using an HPUCO-23A-1550-S-4.5AS collimator (Oz Optics Ltd.), and focused onto the target using a microscope objective (Nikon LU Plan Fluor 10×, $0.30 \mathrm{NA}$ ) with a long working distance of $17.5 \mathrm{~mm}$ [17]. The focused (1/ 
$e^{2}$ ) beam diameter at the flyer surface was $69 \pm 3 \mu \mathrm{m}$ and the confocal parameter was $4.8 \mathrm{~mm}$, so the PDV beam was collimated on the flyer over its entire flight path. The interferogram was detected with $20 \mathrm{GHz}$ amplified photodiodes (Miteq SCMR-100K20G-30-15-10) whose output was digitized with an $8 \mathrm{GHz}$ oscilloscope (Tektronix DPO70804).

\section{Supercontinuum Strobe Source and Imaging Optics}

As depicted in Fig. 4, we tried two imaging geometries. The supercontinuum was gently focused to $\sim 2 \mathrm{~mm}$ in diameter onto the flyer plate optic to create approximately uniform illumination over the $\sim 1.0 \mathrm{~mm}$ field of view seen by the $10 \times$ objective (Fig. 4a). Most images were obtained with grazing-angle illumination (Fig. 4a) where the sample was viewed coaxially while the strobe was incident at $\sim 60^{\circ}$. We also tried coaxial illumination, as depicted in Fig. $4 \mathrm{~b}$, but this proved less useful.

The illuminated sample was imaged through the objective onto an intensified CCD (ICCD) camera (Andor DH $734-18 \mathrm{~F}-33$ ) having a $1024 \times 1024$ array of $13 \mu \mathrm{m}$ pixels. We used a $50 \mathrm{~ns}$ optical gate on the camera to obtain images. The gate acts to suppress ambient lighting. The light returning from the flyer plate was first incident onto a dichroic mirror that reflected visible but transmitted the $1550 \mathrm{~nm}$ near-IR PDV laser, so we could simultaneously obtain flyer images and velocity histories [22, 39].
Figure 4 shows an example of each illumination geometry. These images were taken $\sim 2$ ns after the impact of a $1.0 \mathrm{~km} \mathrm{~s}^{-1}, 75 \mu \mathrm{m} \mathrm{Al}$ flyer with a glass target. With grazing illumination (Fig. 4a), we observed the foil sheet via light scattered at large angles by the foil into the objective. When the flyer impacted the smooth glass surface, it became a higher-reflectivity mirror that scattered less into the objective, so upon impact the flyer became darker while the background maintained a nominally constant brightness. With coaxial illumination (Fig. 4b), the impact again created a higher-reflectivity flyer that reflected more light into the objective than the background foil, so the flyer appeared bright against a darker background.

\section{Reconstructed Movies and Synchronization of Impact and Strobe}

Time-sequenced movies of the flyer launch and impact processes were reconstructed from single frames obtained on different shots at different strobe-impact time delays. This reconstruction process was possible due to the high level of reproducibility, but it should be kept in mind that successive frames of the movies will differ in detail, because each frame looked at a different region of the imperfect metal foil, and because of the stochastic nature of the launch and impact processes.

In order to obtain the most accurate reconstruction, especially at times very close to the instant of impact, we
Fig. 4 Schematic of two geometries for ultrafast microscopy. The objective provides a $1.0 \mathrm{~mm}$ diameter field of view. Images at bottom were taken 2 ns after a $1.0 \mathrm{~km} \mathrm{~s}^{-1}$ impact with a glass target. a With grazing illumination, the metal foil is observed by light scattered into the objective. When the flyer arrives at the window, it appears darker because it becomes a mirror that scatters less light into the objective. b With coaxial illumination, the metal foil is observed by light backscattered into the objective. When the flyer arrives at the window, it reflects more light into the objective and it appears brighter. $O B J 10 \times$ infinitycorrected microscope objective, $D M$ dichroic mirror, $B S$ beam splitter, $P D V$ photon Doppler velocimeter, ICCD intensified charge-coupled device camera
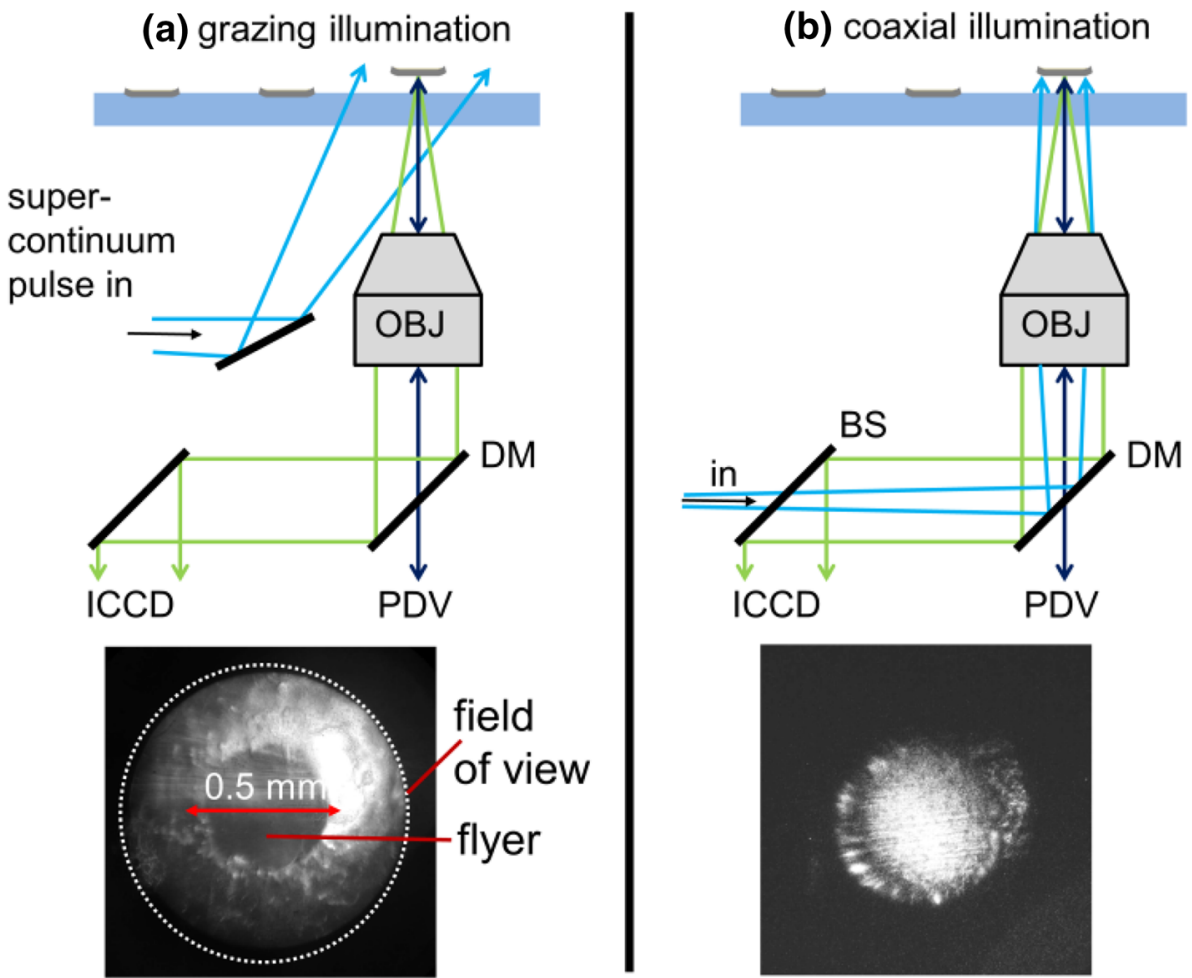
developed a new procedure described in Fig. 5, to synchronize the femtosecond strobe with the target impact as determined by PDV. The launch pulses, the femtosecond strobe pulses and the PDV signals were all detected by photodiodes connected to a common $8 \mathrm{GHz}$ oscilloscope (Fig. 3), but the optical and electronic delays were different for each detector. We determined the PDV-launch pulse delay $\Delta t_{1}$ as described in Fig. 5a and the strobe-launch pulse delay $\Delta t_{2}$ as described in Fig. $5 \mathrm{~b}$. Then we could monitor the launch pulses with photodiode $\mathrm{PD}_{1}$ and the strobe pulses with photodiode $\mathrm{PD}_{2}$ (see Fig. 3) and use the delay generator (Stanford Research Systems DG645) to set the strobe-impact time delay within about $1 \mathrm{~ns}$.

The determination of the PDV-launch pulse delay was described previously [22]. The PDV was aimed at a mirror consisting of a glass window with a $150 \mathrm{~nm} \mathrm{Cr}$ film at the glass target location, and the launch laser was used to vaporize the $\mathrm{Cr}$ film. Since the $\mathrm{Cr}$ ablation occurred with a sharp threshold, the film vaporization and loss of mirror reflectivity was very sudden, creating a sudden drop in the

(a)

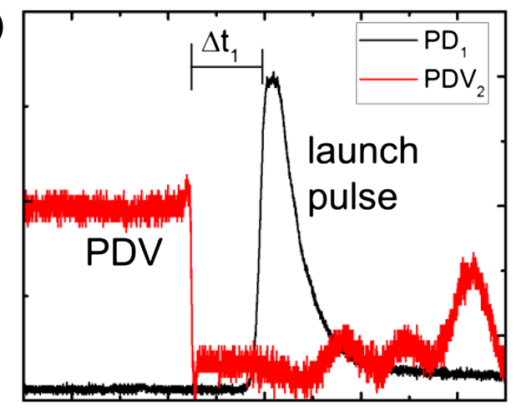

(b)

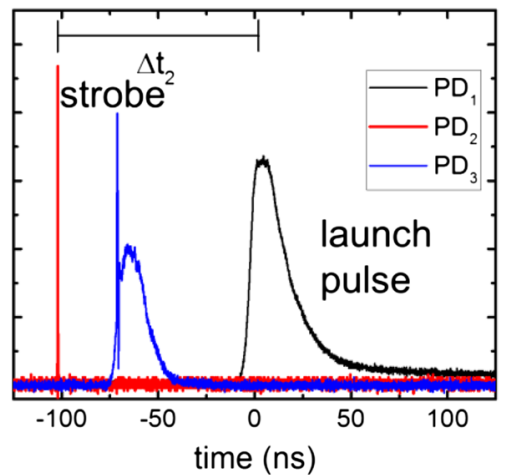

Fig. 5 Synchronization of femtosecond strobe with the flyer plate impact observed by PDV. The photodiodes $\mathrm{PD}_{1}-\mathrm{PD}_{3}$ are defined in Fig. 3. a The time interval $\Delta t_{1}$ between the launch pulse in $\mathrm{PD}_{1}$ and the PDV was determined by aligning the PDV beam on a mirror with a thin $\mathrm{Cr}$ coating and ablating away the coating with the launch laser to cause a sudden decrease in the PDV signal. $\mathbf{b}$ The time $\Delta t_{2}$ between the launch pulse and the strobe pulse was determined by inserting $\mathrm{PD}_{3}$ at the location of the ICCD camera (Fig. 3). PD3 observed light scattered from a ground glass target from the launch and strobe pulses. Knowing $\Delta t_{1}$ and $\Delta t_{2}, \mathrm{PD}_{1}$ and $\mathrm{PD}_{2}$ could be monitored online to determine and control the timing between flyer impact and strobe pulse (Color figure online)
PDV signal (Fig. 5a). The value of $\Delta t_{1}$ was then defined as the time between this sudden PDV transient and the $90 \%$ rise of the launch pulse seen by photodiode $\mathrm{PD}_{1}$.

The determination of the strobe-launch pulse delay $\Delta t_{2}$ used a third photodiode $\mathrm{PD}_{3}$ temporarily inserted in front of the ICCD camera (Fig. 3) to simultaneously monitor the launch pulse and strobe arrival at the glass target, as illustrated in Fig. 5b. The glass target was temporarily replaced with a ground-glass plate to scatter the launch and strobe pulses into $\mathrm{PD}_{3}$. However, since the dichroic optics would not transmit the $1.064 \mu \mathrm{m}$ launch pulse to $\mathrm{PD}_{3}$, we temporarily inserted a second-harmonic crystal in the launch beam path to convert a small portion of the beam to visible $0.532 \mu \mathrm{m}$ light.

\section{Results}

\section{Flyer Velocities and Reproducibility}

Figure 6 shows velocities of flyers versus laser fluence, where the fluence $\left(\mathrm{J} \mathrm{cm}^{-2}\right)$ was computed based on the laser pulse energy incident on the flyer plate optic (up to $2 \mathrm{~J}$ ) and a beam area of $3.8 \times 10^{-3} \mathrm{~cm}^{2}$ (a circle $0.7 \mathrm{~mm}$ in diameter). The maximum available fluence was $500 \mathrm{~J} \mathrm{~cm}^{-2}$. The 25, 50 and $75 \mu \mathrm{m} \mathrm{Al}$ data were published previously [22] and are included for completeness. The 12 and $100 \mu \mathrm{m} \mathrm{Al}$ and 25 and $70 \mu \mathrm{m} \mathrm{Cu}$ data are new. As described previously [22], at the lowest fluences, edge effects became significant and the flyers did not detach from the metal foil sheet. To overcome this problem, we created a flyer plate optic with many $0.7 \mathrm{~mm}$ individual flyer plates, by starting with the usual foil bonded to a window and using a laser milling machine to etch away a ring around each flyer [22]. These flyer plate "cut-outs"

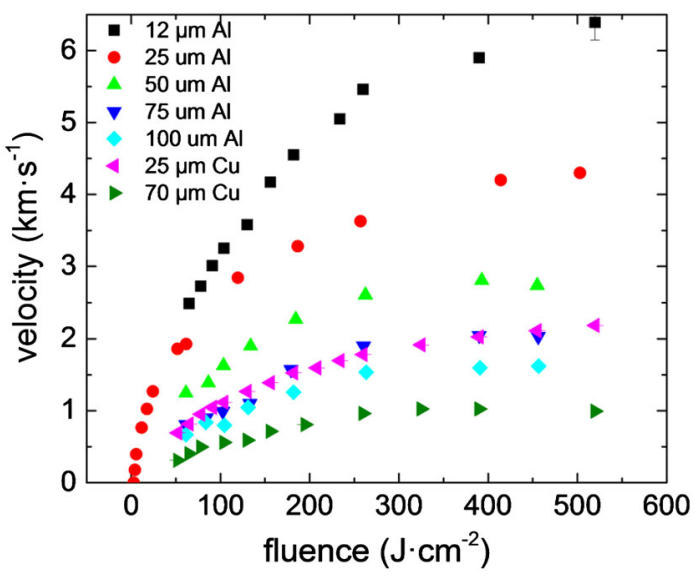

Fig. 6 Measured velocities of flyer plates versus launch laser fluence (Color figure online) 
[22] were used to obtain the $25 \mu \mathrm{m}$ Al data below $2 \mathrm{~km} \mathrm{~s}^{-1}$.

Figure 7 shows the variations (one standard deviation) in flyer velocities and impact times at the glass target for $\mathrm{Al}$ and $\mathrm{Cu}$ flyers. Each data set, consisting of 30-60 shots, was obtained using a single flyer plate optic at the specified launch laser pulse energy. The results are summarized in Table 1. The smallest variations in velocities and impact times were obtained with the $25 \mu \mathrm{m} \mathrm{Al} \mathrm{flyers,} \mathrm{where} \mathrm{the}$ velocity variations were $0.56 \%$ and the impact time variations were $0.81 \mathrm{~ns}$.

\section{Ultrafast Images of Flyer Impacts}

Figure 8 shows a reconstructed movie using grazing illumination, of $25 \mu \mathrm{m} \mathrm{Al}$ flyers at $U_{f}=1.3 \mathrm{~km} \mathrm{~s}^{-1}$ across a $125 \mu \mathrm{m}$ vacuum gap. A representative PDV velocity history is also shown. Notice the scratches and defects on the Al foils vary from image to image. Figure 8 a was obtained prior to launch. Figure $8 \mathrm{~b}$ and $\mathrm{c}$ were obtained during flight, with Fig. 8c obtained just 5 ns before impact. Figure $8 \mathrm{~d}$ was taken $2 \mathrm{~ns}$ after impact. It shows a darker, nearly perfect $0.5 \mathrm{~mm}$ diameter disk in contact with the window. The sudden appearance of this uniform $0.5 \mathrm{~mm}$ disk establishes the high degree of planarity of the impact process over the entire flyer diameter.

Shortly after impact (compare Fig. 8d, e), the flyer diameter increased slightly from 0.5 to $0.6 \mathrm{~mm}$, which we attribute to the delayed arrival of the slower outer ring of
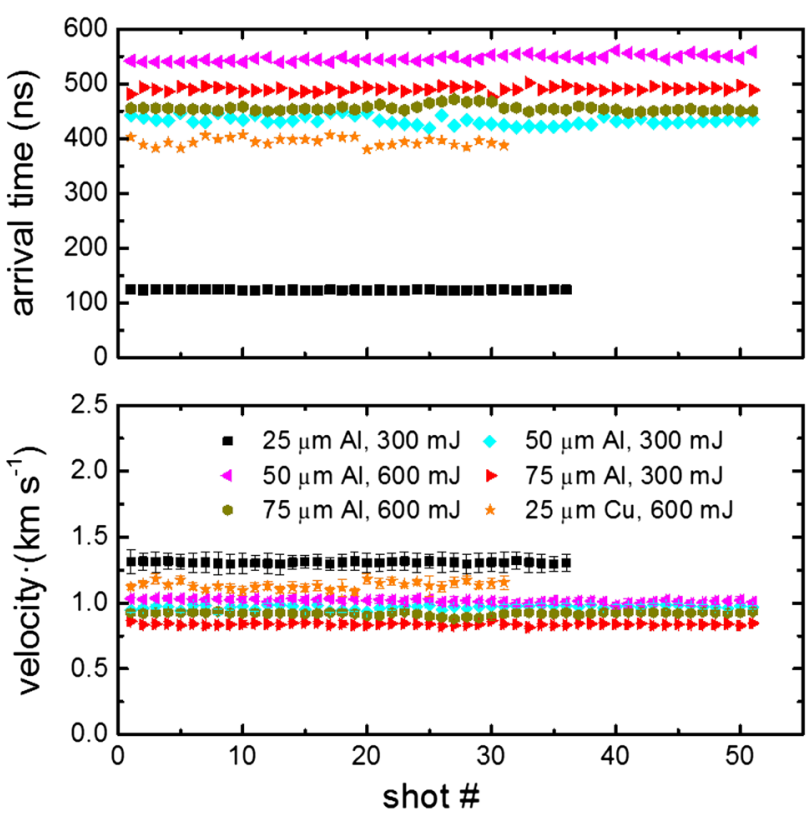

Fig. 7 Impact times at a glass target (top) and variations of flyer plate velocities (bottom), for flyers launched from a single flyer plate optic consisting of a sheet of metal foil bonded to glass (Color figure online) the flyer driven by the soft edges of the launch laser beam, as described by Fig. 1d. After the shock unloaded (e.g. Fig. $8 g-j$ ), the annular region of glass surrounding the flyer plate became brighter. This brighter annulus corresponds to the outer rim of the impact crater in the glass [40]. As the shock spreads radially outward from the flyer, the crushed glass scattered more light back into the objective.

Figure 9 shows the timing diagram for Fig. 10 The strobe was set to the mean time of impact as measured by PDV, and the 35 images in Fig. 10 were obtained at this instant in time. The same conditions as Fig. 8 were used except the flyer speed was a bit faster, $1.4 \mathrm{~km} \mathrm{~s}^{-1}$. Due to the $\pm 0.8 \mathrm{~ns}$ variation in flyer plate impact time, images were randomly obtained no more than $1 \mathrm{~ns}$ before impact or no more than $1 \mathrm{~ns}$ after impact.

Figure 11 shows grazing illumination stroboscopic images of 25, 50 and $75 \mu \mathrm{m}$ thick Al flyers and a $25 \mu \mathrm{m}$ thick $\mathrm{Cu}$ flyer, taken $\sim 2 \mathrm{~ns}$ after impact. These images show all flyer plates as uniform disks in contact with the glass surface. The thicker $\mathrm{Al}$ flyers and the $\mathrm{Cu}$ flyers are all about $0.1 \mathrm{~mm}$ smaller in diameter than the $25 \mu \mathrm{m} \mathrm{Al}$ flyer.

Figure 12 shows one application for these laser-launched flyers, that involves researching the kinetics of impact initiation of explosives. The sample consisted of a fine powder of the explosive HMX (octahydro-1,3,5,7-tetranitro-1,3,5,7-tetrazocine), produced by fluid-energy milling [41], in a $40 \mu \mathrm{m}$ thick layer, against the same kind of glass window used in the other measurements. The emission from a $100 \mu \mathrm{m}$ diameter region at the center of the impact region (Fig. 1b) was detected by a time-resolved spectrometer with 32 wavelength-separated channels described in another publication [42]. Due to the zero problem with logarithmic time bases, the instant of impact was set to $10^{-8} \mathrm{~s}$. When the $25 \mu \mathrm{m}$ Al flyer plate speed was $2.6 \mathrm{~km} \mathrm{~s}^{-1}$, intense emission was observed during the shock in HMX, as shown in Fig. 11a. A second emission burst lasting a few $\mu$ s was observed after a delay of a few hundred ns. When the flyer impacted glass only, minimal emission was observed, showing the flyer plates initiated a powerful chemical reaction in the HMX.

\section{Discussion}

We have shown that our apparatus can launch $0.5 \mathrm{~mm}$ diameter flyer plates made of $\mathrm{Al}$ and $\mathrm{Cu}$ at velocities up to $6.3 \mathrm{~km} \mathrm{~s}^{-1}$, and photograph them with strobe pulses synchronized to the flyer impact. Using a single flyer plate optic, simply consisting of a sheet of metal foil bonded to a glass window, we could launch between 30 and 60 flyers. The number of flyers we could launch depended on how much each flyer launch disturbed the surrounding foil, 
Table 1 Flyer velocities, target impact times and their variations (one standard deviation)

\begin{tabular}{lllllllll}
\hline $\begin{array}{l}\text { Flyer } \\
\text { material }\end{array}$ & $\begin{array}{l}\text { Thick-ness } \\
(\mu \mathrm{m})\end{array}$ & $\begin{array}{l}\text { Number of } \\
\text { shots }\end{array}$ & $\begin{array}{l}\text { Launch laser } \\
\text { energy }(\mathrm{mJ})\end{array}$ & $\begin{array}{l}\text { Launch laser } \\
\text { fluence }\left(\mathrm{J} \mathrm{cm}^{-2}\right)\end{array}$ & $\begin{array}{l}\text { Flight } \\
\text { distance } \\
(\mu \mathrm{m})\end{array}$ & $\begin{array}{l}\text { Velocity } \\
\left(\mathrm{km} \mathrm{s}^{-1}\right)\end{array}$ & $\begin{array}{l}\% \text { velocity } \\
\text { variation }\end{array}$ & $\begin{array}{l}\text { Impact time } \\
(\mathrm{ns})\end{array}$ \\
\hline $\mathrm{Al}$ & 25 & 36 & 300 & 78 & 125 & $1.31( \pm 0.007)$ & 0.56 & $123.8( \pm 0.81)$ \\
$\mathrm{Al}$ & 50 & 51 & 300 & 78 & 375 & $0.97( \pm 0.014)$ & 1.46 & $432.4( \pm 7.5)$ \\
$\mathrm{Al}$ & 50 & 51 & 600 & 156 & 500 & $1.02( \pm 0.012)$ & 1.19 & $546.8( \pm 5.8)$ \\
$\mathrm{Al}$ & 75 & 51 & 300 & 156 & 375 & $0.84( \pm 0.010)$ & 1.19 & $490.3( \pm 5.13)$ \\
$\mathrm{Al}$ & 75 & 51 & 600 & 156 & 375 & $0.92( \pm 0.015)$ & 1.63 & $456.2( \pm 6.86)$ \\
$\mathrm{Cu}$ & 25 & 31 & 600 & & $1.13( \pm 0.02)$ & 2.11 & $394.5( \pm 6.3)$ \\
\hline
\end{tabular}
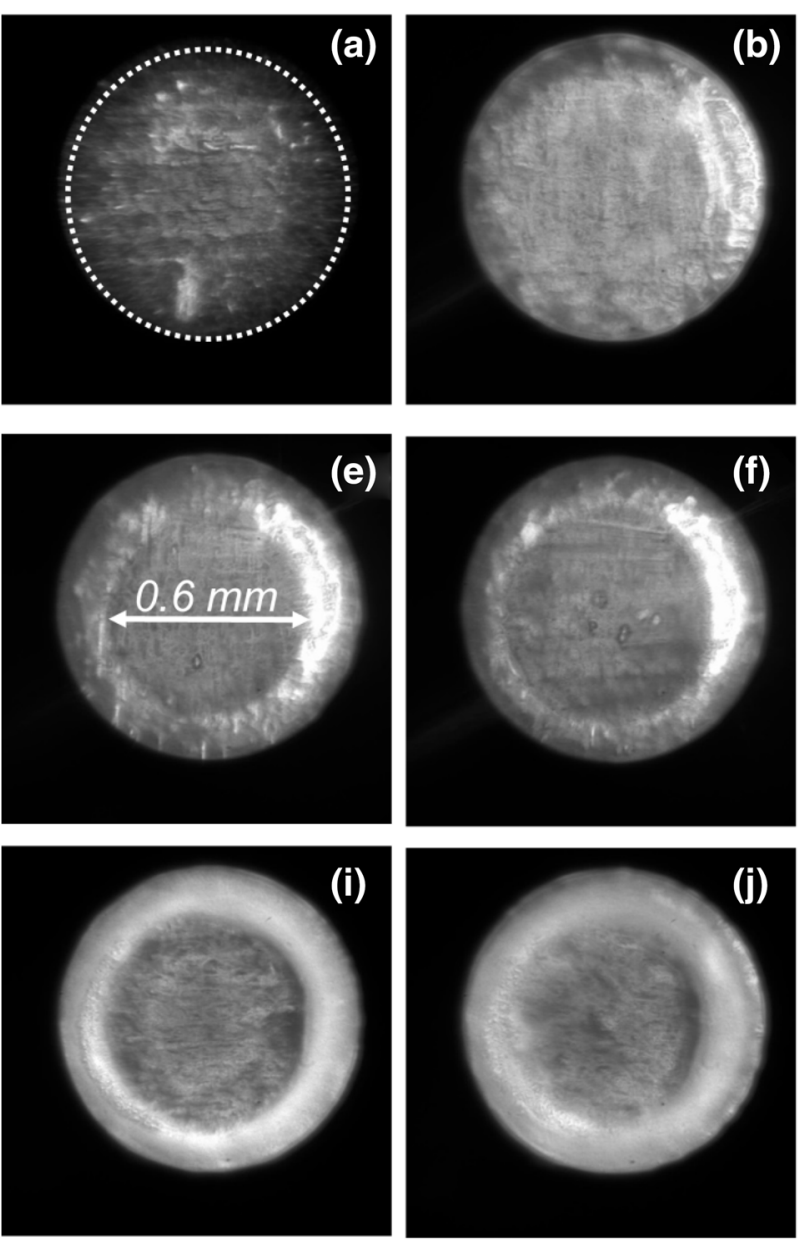
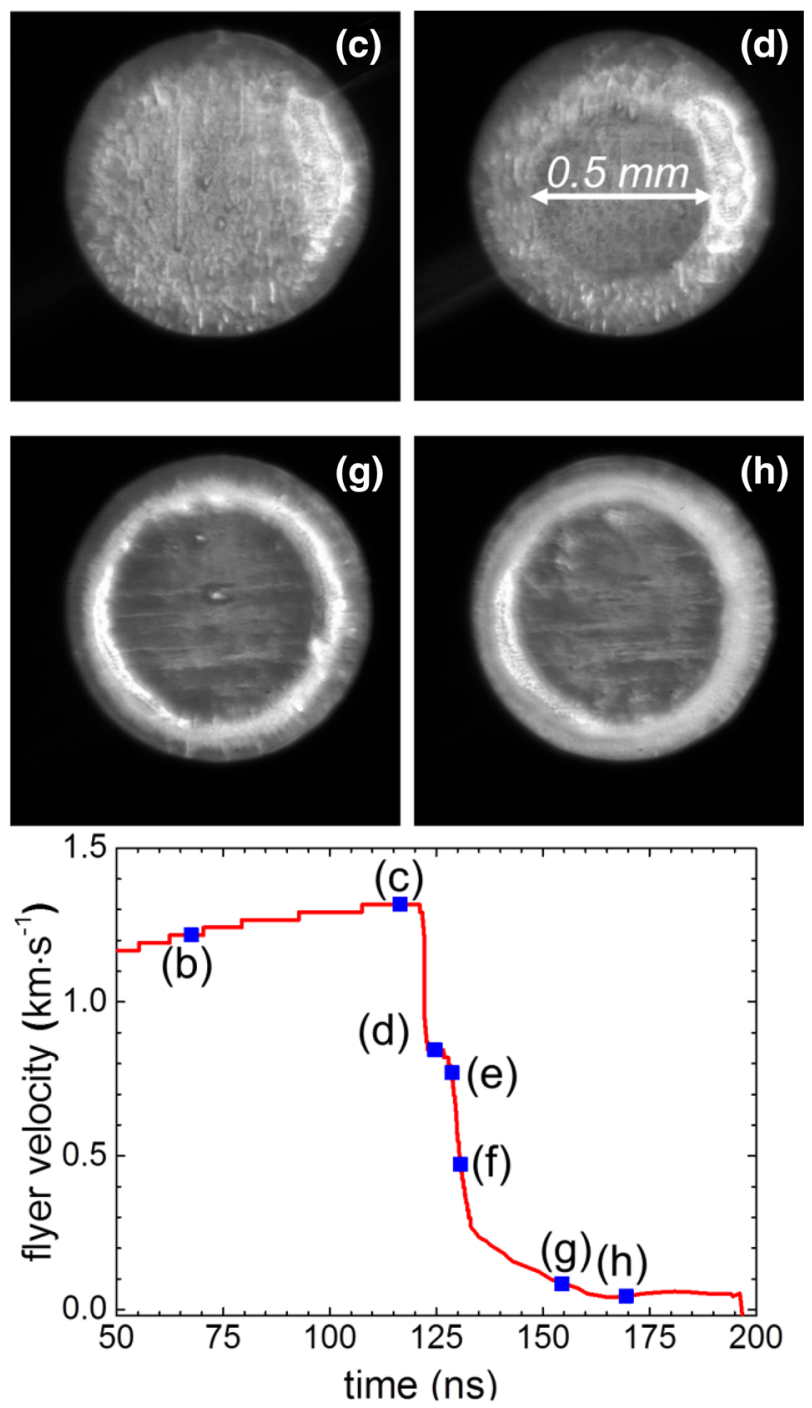

Fig. 8 Ultrafast images of $25 \mu \mathrm{m}$ thick $1.3 \mathrm{~km} \mathrm{~s}^{-1}$ flyers impacting a glass target. A representative PDV trace is shown at bottom right. The strobe was flashed at the times indicated by blue squares. a Prior to launch. The dotted circle indicates the field of view of the microscope

which was greater with thicker flyers and higher-energy launch pulses. The ultrafast optical microscopy data focused primarily on $25 \mu \mathrm{m}$ thick Al flyers launched across objective. b 54 ns before impact. c 5 ns before impact. d 2 ns after impact. e $7 \mathrm{~ns}$ after impact. f $9 \mathrm{~ns}$ after impact. g $33 \mathrm{~ns}$ after impact. h $48 \mathrm{~ns}$ after impact. i $80 \mathrm{~ns}$ after impact. j $155 \mathrm{~ns}$ after impact (Color figure online)

a short $125 \mu \mathrm{m}$ gap, because those conditions gave the best and most reproducible results, but results for other flyers that were hardly worse were also presented. 


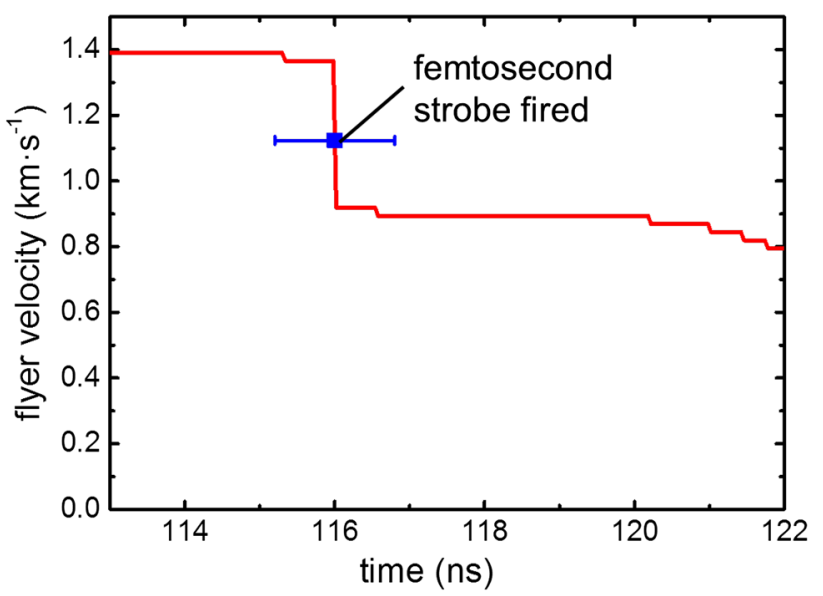

Fig. 9 Timing diagram for Fig. 10. A series of $25 \mu \mathrm{m}$ thick Al flyers were launched from the same flyer plate optic at a glass target at $1.4 \mathrm{~km} \mathrm{~s}^{-1}$, and images were acquired by femtosecond strobe pulses arriving at the mean time of impact, as denoted by the blue square on this typical PDV velocity history (Color figure online)

\section{Flyer velocities}

Besides the velocity versus laser fluence results in Fig. 6, there were two notable observations, the lower speed cutoff and the variability among flyer plate optics described in Fig. 7 and Table 1. The lower speed cut-off results from edge effects. At lower laser fluences, a portion of the foil will puff out from the glass substrate but a flyer will not detach. This occurs when the fluence is not high enough to overcome the cohesion at the perimeter of the flyer disk [22]. As shown in Fig. 6, we did not obtain much data for flyers launched below $0.5 \mathrm{~km} \mathrm{~s}^{-1}$. The exception was the $25 \mu \mathrm{m}$ thick $\mathrm{Al}$ data, where we made a special effort to fabricate a flyer plate optic with detached discrete $700 \mu \mathrm{m}$ flyers [22]. Then we were able to launch flyers as slow as $0.1 \mathrm{~km} \mathrm{~s}^{-1}$. We presume that the discrete flyer arrangement would work for the other foils, but we have not demonstrated it.

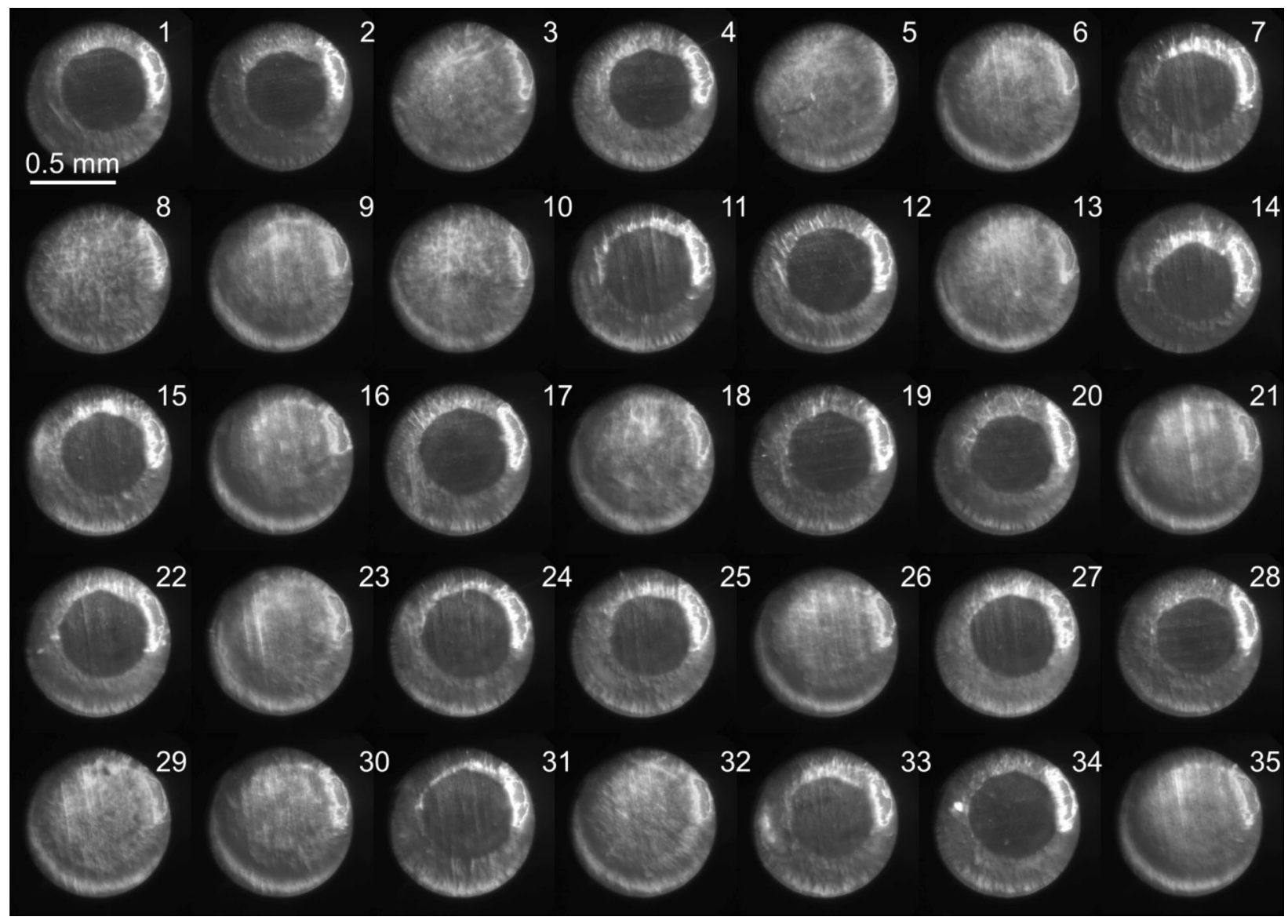

Fig. 10 Ultrafast images of $25 \mu \mathrm{m}$ thick $1.4 \mathrm{~km} \mathrm{~s}^{-1}$ Al flyers impacting a glass target, obtained with 35 consecutive shots from the same flyer plate optic. The strobe pulse was set to the mean instant of impact. Due to the \pm 0.8 ns variation in impact time, images were randomly obtained just prior to and just after impact 

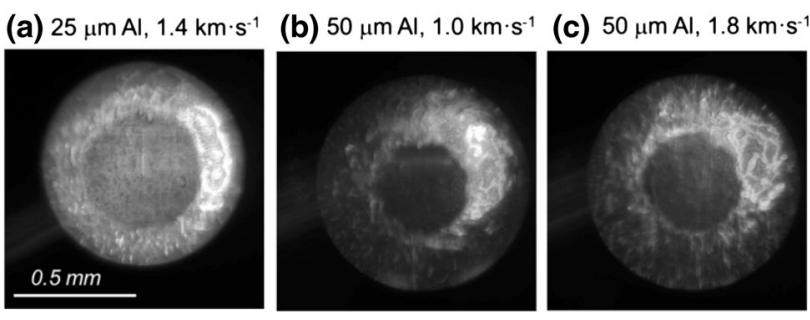

(d) $75 \mu \mathrm{m} \mathrm{Al}, 1.5 \mathrm{~km} \cdot \mathrm{s}^{-1}$

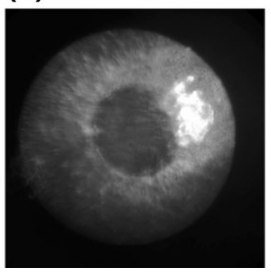

(e) $25 \mu \mathrm{m} \mathrm{Cu}, 1.2 \mathrm{~km} \cdot \mathrm{s}^{-1}$

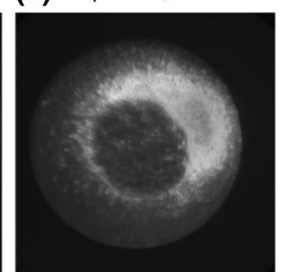

Fig. 11 Images of flyers taken $2 \mathrm{~ns}$ after impacting a glass target. The $25 \mu \mathrm{m}$ flyer diameter was the same as the $0.5 \mathrm{~mm}$ uniform part of the launch laser beam. The thicker $\mathrm{Al}$ and $\mathrm{Cu}$ flyer diameters were about $20 \%$ smaller due to edge effects resulting from cohesive forces as the flyers were torn away from the foil sheet

At a given laser fluence, different flyer plate optics launched flyers at slightly different velocities. An example is shown by the data in Figs. 8 and 9, where $25 \mu \mathrm{m} \mathrm{Al}$ flyers were launched with $300 \mathrm{~mJ}$ pulses. In the first case the speed was $1.3 \mathrm{~km} \mathrm{~s}^{-1}$ and in the second $1.4 \mathrm{~km} \mathrm{~s}^{-1}$. We believe this variability results from random variability in the glass surface quality. The laser drive pulses are absorbed at the glass/epoxy interface (Fig. 1), the amount of energy absorbed and the flyer speed depends on the glass surface damage threshold [14, 15, 22], and the manufacturer does not control for this property. If we want to perform experiments at a particular flyer speed, we have to take a few ranging shots initially to determine the behavior of each flyer plate optic.

\section{Velocity and Impact Time Variations}

When 30-60 flyers were launched from a single flyer plate optic at a constant laser fluence, the velocities varied slightly. As shown in Table 1, the fractional variations ranged from 0.56 to $2.11 \%$. We believe the primary cause of velocity variations $>0.5 \%$ is foil quality and the care taken to bond the foil to the glass substrate. The $25 \mu \mathrm{m} \mathrm{Al}$ foils were smoother and shinier than the thicker foils, and easier to bond uniformly, so those generally gave the best results.

The impact time variations depend on the velocity variations, and they are proportional to the flight distance and inversely proportional to the flight velocity. The choice of gap thickness depends on the acceleration and reverberation damping profile of the flyer launch, as illustrated in Fig. $2 b$ and as described in detail previously [17]. The
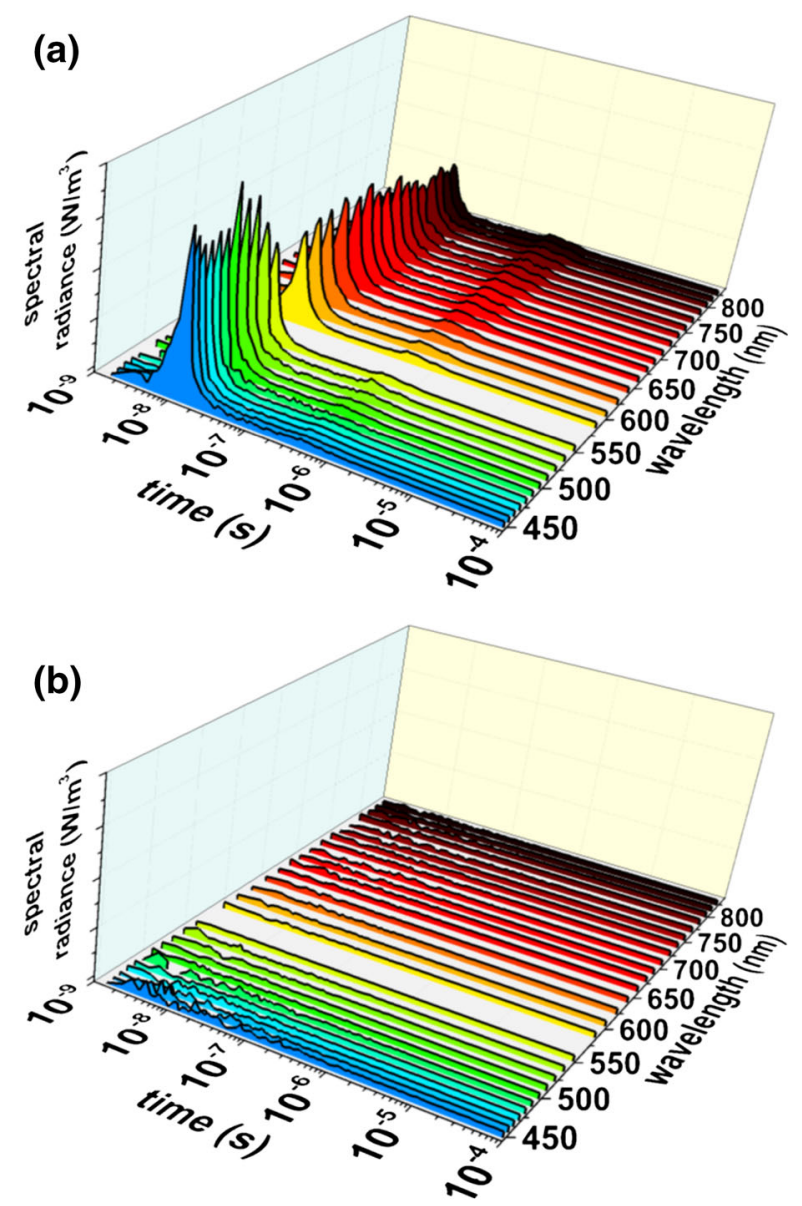

Fig. 12 Time-dependent emission spectra of a $40 \mu \mathrm{m}$ thick layer of HMX fine powder on glass after impact with a $25 \mu \mathrm{m}$ thick Al flyer at $2.58 \mathrm{~km} \mathrm{~s}^{-1}$. a HMX emission. b Glass emission at the same impact velocity. Due to the $\log$ (time) axis, time was shifted so that $10^{-8} \mathrm{~s}$ denoted the instant of flyer impact (Color figure online)

reverberation damping is faster with thinner foils, and in our 1.3-1.4 $\mathrm{km} \mathrm{s}^{-1} 25 \mu \mathrm{m} \mathrm{Al} \mathrm{flyer} \mathrm{measurements,} \mathrm{we} \mathrm{were}$ able to use a small gap of $125 \mu \mathrm{m}$. These conditions produced the smallest impact time variations of $0.8 \mathrm{~ns}$. In other, less favorable cases, those variations were seen to be as large as $7.5 \mathrm{~ns}$, as seen in Table 1.

\section{Flyer Flatness and Tilt}

The most comprehensive information regarding flyer flatness and tilt can be derived from Fig. 10, which show 35 images obtained with the strobe set to the mean time of impact. Due to impact time variations, images randomly were obtained $<1$ ns before impact when flyer plates were practically invisible, or $<1 \mathrm{~ns}$ after impact where the flyers could be easily seen. In the post-impact images, the flyer plates were always uniform disks $\sim 0.5 \mathrm{~mm}$ in diameter.

To interpret the data in Fig. 10, consider what would be observed in the collision between a $0.5 \mathrm{~mm}$ flyer with a 
glass target if the two surfaces were flat and parallel. In the grazing-incidence geometry, when the flyer plate approaches the glass within about one visible wavelength $\lambda \approx 0.5 \mu \mathrm{m}$, it creates a mirror-like surface that reduces the strobe light scattered back into the microscope objective, causing a dark $0.5 \mathrm{~mm}$ disk to appear. When the flyer velocity was $1.4 \mathrm{~km} \mathrm{~s}^{-1}$, the time interval between this close approach and impact would be only $350 \mathrm{ps,} \mathrm{so} \mathrm{we}$ will ignore it.

On the other hand, if the flyer were tilted, then at shorter times we would not see a disk, we would see a partial disk. For instance, at an instant when only one-half of the flyer was in contact with the glass target, we would see a halfmoon shape. If a flyer were not flat, for instance if its surface had hills and valleys, then as the flyer came into contact with the glass target we would see dark hills and brighter valleys. These conditions, partial disks, hills and valleys were never observed in Fig. 10. We observed only uniform disks or no disks. In fact every post-impact image (19/38) was a nearly perfect disk. This indicates the impact tilt is very small and the flyer plates are flat at impact.

Although we cannot quantitatively determine the tilt and flatness from the data in Fig. 10, we can estimate it. In all the post-impact images in Fig. 10, the entire $0.5 \mathrm{~mm}$ flyer disk must be within $0.5 \mu \mathrm{m}$ of the glass target and PDV shows flight to impact in $<0.5 \mathrm{~ns}$. This implies a tilt of $<1$ mrad for every impact.

\section{Flyer Diameters}

The flyer diameters should be affected by two types of edge effects, one arising from the soft edges of the launch laser beam and the other from cohesive forces within the metal foils that inhibit tearing away a flyer disk from the foil sheet.

As described in Fig. 1, the launch laser beam had a $0.5 \mathrm{~mm}$ flat region and soft edges that extended to about $0.7 \mathrm{~mm}$. Thus based solely on this beam profile, our initial expectation would be that we should launch $0.5 \mathrm{~mm}$ flyers accompanied by an outer ring, extending out to perhaps $0.6-0.7 \mathrm{~mm}$, that moved at slower velocities. That appears to be the case, as shown in Fig. 8 for $25 \mu \mathrm{m}$ Al flyers. The initial impact created a disk that was $0.48 \mathrm{~mm}$ in diameter (Fig. 8d), but 5 ns later (Fig. 8e) the disk had enlarged to $0.6 \mathrm{~mm}$ in diameter.

When thicker $\mathrm{Al}$ or $25 \mu \mathrm{m}$ thick $\mathrm{Cu}$ flyers were launched, as shown in Fig. 11, the disks appearing on the glass target were noticeably smaller, about $20 \%$ smaller, than with the $25 \mu \mathrm{m} \mathrm{Al}$ flyers. Based on Fig. 11, we conclude that edge cohesion effects reduced the diameter of the planar flyer plates launched from these foils to slightly less than the $0.5 \mathrm{~mm}$ diameter of the uniform part of the launch beam.

\section{Summary and Conclusions}

In this study, we used PDV to determine the velocity range for $\mathrm{Al}$ and $\mathrm{Cu}$ flyers launched from a simple flyer plate optic consisting of a metal foil bonded to a glass window, employing a shock launch mechanism that creates cold, intact flyers. With a single flyer plate optic, we can launch 30-60 flyers. The launch process shows a high degree of reproducibility, in the case of $25 \mu \mathrm{m}$ thick Al flyers the velocity variations for 36 launches were $0.56 \%$. Other $\mathrm{Al}$ flyer plate optics had slightly worse velocity variations of $1-1.5 \%$. The $\mathrm{Cu}$ flyers had the largest velocity variations of $2.11 \%$. We believe we could improve the velocity variations $>0.5 \%$ by devoting more effort to fabricating more perfect flyer launch optics, but the simple methods we used seem adequate for most applications.

The impact time with a glass target after flying across a vacuum gap also showed a high degree of reproducibility. With the $25 \mu \mathrm{m}$ Al flyers launched across a minimal $125 \mu \mathrm{m}$ gap, the impact time variation was just $0.8 \mathrm{~ns}$.

Ultrafast strobe photography, using an amplified femtosecond laser interfaced with the nanosecond launch laser, provided information about the uniformity and tilt of the flyer impact with a flat glass target. In the case we studied the most, which was the best case, $25 \mu \mathrm{m} \mathrm{Al} \mathrm{flyers}$ exhibited a high degree of flatness and minimal tilt. The tilt in this case was estimated to be $<1 \mathrm{mrad}$.

The simple foil sheet method does create edge effects when the flyers tear themselves away from the sheet. Edge effects limit our ability to launch flyers at lower speeds $<0.5 \mathrm{~km} \mathrm{~s}^{-1}$ due to the inhibiting effects of foil cohesion. Edge effects also reduce the effective flyer diameter by about $20 \%$ when the uniform part of the launch beam was $0.5 \mathrm{~mm}$. These effects can be mostly eliminated using individual flyer cut-outs, but that increases the fabrication time significantly.

The reproducibility, planarity and tilt values obtained here for laser-launched thin foils compare well with the most precise gas guns, and the laser-launched foil apparatus can support many more shots, often 100 per day. The primary limitation of this system is the limited duration of the shock pulses, which are generally $<20 \mathrm{~ns}$. For this reason, this apparatus is well-suited to understanding the shorter-time behavior of shocked media in greater detail than has been possible previously [20, 43, 44]. One example application briefly described here is the use of this apparatus to study the shorter-time behavior of impact initiation of the high explosive HMX. The ability of an impactor to initiate explosives depends both on shock pressure and shock duration. A $P^{2} t=$ constant relation is most commonly used to describe explosives initiation thresholds $[45,46]$, so, for example, the shock 
pressure must be increased by four if the duration is reduced by two. As we have shown in Fig. 12, despite the limited duration of shocks produced by the thin flyer plates, it is still possible to initiate explosive chemistries in high explosives.

Acknowledgments The research described in this study was based on work supported by the US Army Research Office under award W911NF-13-1-0217, the US Air Force Office of Scientific Research under awards FA9550-14-1-0142 and FA9550-16-1-0042, the Defense Threat Reduction Agency under award HDTRA1-12-1-0011, and the Office of Naval Research under award N00014-12-1-0828. William L. Shaw and Will P. Bassett acknowledge support from the Stewardship Sciences Academic Alliance Program from the Carnegie-DOE Alliance Center, under DOE award DE-NA0002006.

\section{References}

1. He H, Sekine T, Kobayashi T, Kimoto K (2001) Accurate measurement of the velocity history of a laser-driven foil plate with a push-pull-type VISAR. Appl Opt 40:6327-6333

2. Tanaka KA, Hara M, Ozaki N, Sasatani Y, Kondo K, Nakano M, Nishihara K, Takenaka H, Yoshida M, Mima K (2000) Multilayered flyer accelerated by laser induced shock waves. Phys Plasma 7:676-680

3. Cagnoux J, Chartagnac P, Hereil P, Perez M (1987) Lagrangian analysis. Modern tool of the dynamics of solids. Ann Phys Fr $12: 451-524$

4. Forbes JW (2012) Shock wave compression of condensed matter. A primer. Springer, New York

5. Mashimo T, Sawaoka A (1981) A measurement system for interior projectile motion and particle-velocity histories for impact shock study with a two-stage light gas gun. Jpn J Appl Phys 20:963-970

6. Fowles GR, Duvall GE, Asay J, Bellamy P, Feistmann F, Grady D, Michaels T, Mitchell R (1970) Gas gun for impact studies. Rev Sci Instrum 41:984-996

7. Gupta YM, Keough DD, Walter DF, Dao KC, Henley D, Urweider A (1980) Experimental facility to produce and measure compression and shear waves in impacted solids. Rev Sci Instrum 51:183-194

8. Ito K, Aizawa T, Paisley DL (1998) Laser-driven shock device for real-time Hugoniot measurement. Rev High Press Sci Technol 7:876-878

9. Paisley DL, Luo S-N, Greenfield SR, Koskelo AC (2008) Laser-launched flyer plate and confined laser ablation for shock wave loading: validation and applications. Rev Sci Instrum 79:023902

10. Swift DC, Niemczura JG, Paisley DL, Johnson RP, Luo S-N, Tierney TE IV (2005) Laser-launched flyer plates for shock physics experiments. Rev Sci Instrum 76:093907

11. X-h Zhao, Zhao X, G-c Shan, Gao Y (2011) Fiber-coupled laserdriven flyer plates system. Rev Sci Instrum 82:043904

12. Watson S, Field JE (2000) Integrity of thin, laser-driven flyer plates. J Appl Phys 88:3859-3864

13. Yu H, Fedotov V, Baek W, Yoh JJ (2014) Towards controlled flyer acceleration by a laser-driven mini flyer. Appl Phys A 115:971-978

14. Greenaway MW, Proud WG, Field JE, Goveas SG (2002) The development and study of a fiber delivery system for beam shaping. Rev Sci Instrum 73:2185-2189

15. Greenaway MW, Proud WG, Field JE, Goveas SG (2003) A laser-accelerated flyer system. Int J Impact Eng 29:317-321
16. Strand OT, Goosman DR, Martinez C, Whitworth TL, Kuhlow WW (2006) Compact system for high-speed velocimetry using heterodyne techniques. Rev Sci Instrum 77:083108

17. Curtis AD, Banishev AA, Shaw WL, Dlott DD (2014) Laserdriven flyer plates for shock compression science: launch and target impact probed by photon Doppler velocimetry. Rev Sci Instrum 85:043908

18. Curtis AD, Dlott DD (2014) Dynamics of shocks in laser-launched flyer plates probed by photon Doppler velocimetry. J Phys: Conf Ser 500:192002

19. Weng J, Wang XX, Ma Y, Tan H, Cai L, Li J, Liu C (2008) A compact all-fiber displacement interferometer for measuring the foil velocity driven by laser. Rev Sci Instrum 79:113101

20. Banishev AA, Shaw WL, Dlott DD (2014) Dynamics of polymer response to nanosecond shock compression. Appl Phys Lett 104:101914

21. He H, Kobayshi T, Sekine T (2001) Time-resolved measurement on ablative acceleration of foil plates driven by pulsed laser beam. Rev Sci Instrum 72:2032-2035

22. Brown KE, Shaw WL, Zheng X, Dlott DD (2012) Simplified laser-driven flyer plates for shock compression science. Rev Sci Instrum 83:103901

23. Frank AM, Trott WM (1994) Stop motion microphotography of laser driven plates. SPIE, San Diego

24. Lawrence RJ, Trott WM (1993) Theoretical analysis of a pulsedlaser-driven hypervelocity flyer launcher. Int J Impact Eng 14:439-449

25. Trott WM (1996) High-speed optical studies of the driving plasma in laser acceleration of flyer plates. AIP Conf Proc 370:921-924

26. Paisley DL, Luo SN, Swift DC, Greenfield S, Loomis E, Johnson R, Peralta P, Koskelo A, Tonks D (2007) Experimental method for laser-driven flyer plates for 1-D shocks. AIP Conf Proc 955:1337-1340

27. Trott WM, Meeks KD (1990) High-power Nd: glass laser transmission through optical fibers and its use in acceleration of thin foil targets. J Appl Phys 67:3297-3301

28. Rupp TD, Gehr RJ, Bucholtz S, Robbins DL, Stahl DB, Sheffield SA (2003) Stereo camera system for three-dimensional reconstruction of a flyer plate in flight. Rev Sci Instrum 74:5274-5281

29. Greenfield SR, Luo SN, Paisley DL, Loomis EN, Swift DC, Koskelo AC (2007) Transient imaging displacement interferometry applied to shock loading. AIP Conf Proc 955:1093-1096

30. Stahl DB, Paisley DL (1994) Carbon-assisted flyer plates. In: U.P. Office (ed). Washington, DC, US Department of Energy

31. Jensen BJ, Holtkamp DB, Rigg PA, Dolan DH (2007) Accuracy limits and window corrections for photon Doppler velocimetry. J Appl Phys 101:013523

32. Barker LM (1972) Laser interferometry in shock-wave research. Exp Mech 12:209-215

33. Shaw WL, Curtis AD, Banishev AA, Dlott DD (2014) Laserdriven flyer plates for shock compression spectroscopy. J Phys 500:142011

34. Marsh SP (1980) LASL shock Hugoniot data. University of California Press, Berkeley

35. W-1 Liu, Bassett WP, Christensen JM, Dlott DD (2015) Emission lifetimes of a fluorescent dye under shock compression. J Phys Chem A 119:10910-10916

36. Liu W-1, Christensen JM, Bassett WP, Dlott DD (2015) Photophysics of fluorescent probes under shock compression. AIP Conf Proc (in press)

37. Khare R, Shukla PK (2010) Temporal stretching of laser pulses. In: Duarte FJ (ed) Coherence and ultrashort pulse laser emission. InTech, Rijeka

38. Alfano RR (1989) The supercontinuum laser source. Springer, New York 
39. Brown KE, Fu Y, Shaw WL, Dlott DD (2012) Time-resolved emission of dye probes in a shock-compressed polymer. J Appl Phys 112:103508

40. Fujiwara H, Brown KE, Dlott DD (2010) High-energy flat-top beams for laser launching using a Gaussian mirror. Appl Opt 49:3723-3731

41. Welle EJ, Molek CD, Wixom RR, Samuels P (2014) Microstructural effects on the ignition behavior of HMX. J Phys 500:052049

42. Bassett WP, Dlott DD (2015) 32-channel pyrometer with high dynamic range for studies of shocked thermites. AIP Conf Proc (in press)
43. Banishev AA, Dlott DD (2014) Ultrafast pressure-sensitive paint for shock compression spectroscopy. J Appl Phys 115:203515

44. Christensen JM, Banishev AA, Dlott DD (2014) Bright emissive core-shell spherical microparticles for shock compression spectroscopy. J Appl Phys 116:033513

45. Andersen WH (1984) Approximate method of calculating critical shock initiation conditions and run distance to detonation. Propellants Explos Pyrotech 9:39-44

46. Walker FE, Walsey RJ (1976) A general model for the shock initiation of explosives. Propellants Explos Pyrotech 1:73-80 